\title{
Assessing Ethical Discourses on Human Enhancement from the Point of View of the Democratization of Science and Technology
}

\author{
Analizando el discurso ético sobre la mejora humana desde \\ el punto de vista de la democratización de la ciencia y la \\ tecnología
}

\author{
PALOMA GARCÍA DÍAZ \\ Department of Philosophy I, University of Granada, Spain
}

\begin{abstract}
In this article I analyze a bias deriving from the principles employed within ethical discourses on «human enhancement», and which relates to positivism. I begin by sketching the two main positions that shape the ethical debate on human enhancement: a creative, posthumanist or pro-enhancement position as against a bioconservative or gratitudeoriented position. My aim is to show, firstly, that the ethical debate on human enhancement, especially within the pro-enhancement camp, arises from an excessively optimistic, even naive, view of science and technology; and, secondly, that there is little attention paid to the epistemological, social and political questions surrounding this debate.

KEYWORDS

BIOCONSERVATISM, HUMAN ENHANCEMENT, POSTHUMANISM, SCIENCE AND TECHNOLOGY STUDIES

\section{RESUMEN}

En este artículo analizo ciertos problemas que se derivan de los principios que se utilizan en el discurso ético sobre la «mejora-humana», y que guardan relación con el positivismo. Comienzo esbozando las dos posiciones principales que configuran el debate sobre la mejora-humana: la posición creativa, post-humanista o pro-mejora frente a la postura bio-conservadora u orientada a la gratitud. Mi objetivo es mostrar, primero, que el debate ético sobre la mejora-humana proviene, especialmente en el bando pro-mejora, de una visión demasiado optimista, casi ingenua, de la ciencia y de


la tecnología; y segundo, que este debate ha prestado poca atención a las cuestiones epistemológicas, sociales y políticas que están en juego.

PALABRAS CLAVE

BIOCONSERVADURISMO, MEJORA HUMANA, POSTHUMANISMO, ESTUDIOS EN CIENCIA Y TECNOLOGÍA

\section{INTRODUCTION}

Human enhancement issues touch on a great variety of disciplines, such as utopian and dystopian thought, politics, science fiction, sport, medicine and, more recently, (bio)ethics (Savulescu 2009). Furthermore, scholars interested in the ongoing research, analysis and reflection on human enhancement must deal with a large array of topics such as extending lifespan, improving human cognition or other biological and psychological functions, cloning, preconception and prenatal sex selection, in addition to mood enhancements and enhancements with important moral implications. Human enhancement issues, therefore, cross over into different realms, such as biology, psychology, medicine, genetic engineering, sport, society, culture, legislation and morality. Moreover, human enhancement raises questions about human nature, human expectations, human identity and social justice. Supporters of human physical, psychological and moral upgrading through drugs (pharmaceutically developed neuroenhancements such as modafinil or oxytocin), biomedical techniques, genetic engineering, nanotechnology and artificial intelligence are called posthumanists or transhumanists (Bostrom 2005a; 2005b; Parens 2005). In this context, posthumanism is thus a synonym for transhumanism. The first principle of the «The Transhumanist Declaration» by Nick Bostrom states that: «Humanity will be radically changed by technology in the future. We foresee the feasibility of redesigning the human condition, including such parameters as the inevitability of aging, limitations on human and artificial intellects, unchosen psychology, suffering, and our confinement to the planet earth» (Bostrom 2005b, 21).1

1 Nonetheless, posthumanism does not only have to do with the promotion of so-called transhumanity. Feminist and philosopher of science Donna Haraway -and, among others, cultural studies scholars such as Cary Wolfe- use the term «posthumanism» in order to speak about what comes after humans in the age of technoscientific developments. The relationships between natural and artificial, humans and animals, technological and biological beings are at the center of posthumanist thought. What characterizes this kind of posthumanism is a postmodern background and a skeptical and ironic reflection on the construction of reality (Wolfe 2009). 
In this article I analyze a principle related to positivism that causes bias, and that is operating within ethical discourses on human enhancement. In so doing, I first discuss, in a broad sense, the two primary positions that shape the ethical debate on human enhancement: a creative, posthumanist or pro-enhancement framework which is in opposition to a bioconservative or gratitude framework (Parens 2005, 37; Nielsen 2011, 21). Secondly, I distinguish three techniques of human enhancement, in order to differentiate the paradigmatic cases that come up in the debate about the enhancement of human capacities, on the one hand, from the debate about enhancing humans in order to build transhumans (Bostrom 2005b), on the other. Thirdly, I highlight a positivist stance within the creative, posthumanist or pro-enhancement framework, and which excludes social and political questions from ethical discourses on human enhancement. Finally, I assess certain features of the creative and the bioconservative frameworks, from the point of view of the democratization of the science and technology program within Science and Technology Studies (STS).

My aim is to show, firstly, that the ethical debate on human enhancement, especially within the pro-enhancement camp, arises from an optimistic view of science and technology and, secondly, that there is little attention paid to the epistemological, social and political questions that surround this position. I suggest that this issue deserves a more complete inquiry. I propose the principle of non-isolationism, which would serve to explore the entanglements between the epistemological, social and political aspects of human enhancement within the ethical debate. I also argue for the necessity of rethinking the ethical debate on human enhancement from the perspective of a new framework.

\section{THE GRATITUDE AND CREATIVE ETHICAL FRAMEWORKS}

Scholars currently tackle the ethical debate on human enhancement from the perspectives of two primary ethical frameworks: a bioconservative or gratitude framework and a posthuman or creative one.

The gratitude framework, in a broad sense, stresses the dignity of (human) nature and autonomy, and fears that enhancement of human capacities will attack harmony in nature and will violate certain human rights, especially equality and freedom (Ida 2009; Shimazono 2009). The bioconservatives' nightmares relate to the transformation of human nature and focus on issues such as a lack of identity or autonomy (Lilley 2013, 10). Those problems underlie the ethical debate on mood enhancement and lifespan extension (Juth 2011; Temkin 2011). In addition, the bioconservatives' claims are strongly affected by a humanist prejudice, such as 
that found in Bernard Williams, and which is criticized in turn by posthumanists (Savulescu 2009). Briefly, from a bioconservative point of view, enhancement technologies threaten our efforts to achieve human authenticity. The possibility that humans could be designed by genetic engineering and that pharmaceutical neuroenhancements could improve our mood and shape our traits of character would, for bioconservatives, fundamentally undermine such human features such as intellectual and moral effort. Posthumanists are playing God, runs the argument, because they do not accept human limitations and vulnerabilities. Human authenticity thus implies accepting the results of the human genetic lottery and valuing human intellectual, political, moral and artistic achievements (Sandel 2009).

The creative framework, on the other hand, focuses on technoscientific improvements of human capacities. Supporters of the creative framework welcome cognitive, moral and mood enhancements, as well as enhancements that affect sport, physical appearance and human functioning: these enhancements are feasible, their effectiveness is supported by current research and they do not entail more drawbacks than advantages in terms of health risks (Harris 2009; Singer 2009). In addition, scholars within the creative framework argue in favor of requiring a moral justification for human enhancements, and they challenge certain policies, which they see as unjustifiably conservative, and as deriving from an unjustified fear of reason, science, and development (Harris 2009, 31-32; Savulescu and Foddy 2011, 310).

Eric Parens argues that both detractors and proponents of human enhancement are loyal to a moral ideal of authenticity, which relates to the idea that "we are authentic when we exhibit or are in possession of what is most our own: Our own way of flourishing or being fulfilled. To be separated from what is most our own is to be in a state of alienation» (Parens 2009, 184). Many questions arise from the previously mentioned prejudice towards the moral ideal of authenticity. Eric Parens suggests that both ethical frameworks deserve equal respect because, he thinks, everybody is continuously «moving between frameworks» since none of us feel confortable in only one of them. Parens highlights the values of openness and thoughtfulness that stem from moving between frameworks (Parens 2009, 189). He therefore concludes that the assumption of our ambivalence and the exploration of how we value and appreciate elements of both ethical frameworks will be helpful in leading to a more fruitful debate about enhancement. In sum, he argues that we should aspire to a balance between the commitments and insights of both the gratitude and the creative frameworks (Parens 2009, 191).

However, he only briefly brings up questions such as: What does selffulfillment mean? Or, how should we understand human flourishing? In my 
view, the moral ideal of authenticity -which is a prior bias that prejudices the assessment of human enhancement- leads us not only to the issues highlighted by Parens but also to questions like: Is it possible to imagine an ideal of authentic personhood that functions independently of a determinate social context? What role does technology play in the transformation of human functioning? Should we always inquire about how human nature would be positively or negatively affected by the enhancement technologies that are to be used as means? Or is it possible to consider and assess enhancement technologies exclusively on the basis of their being good or evil means? Those questions lead to moral, social, political, as well as epistemological inquiries. Furthermore, I will argue that the entanglement between socio-technical, political and ethical and legal issues will require a methodological principle that will ground inquiries concerning human enhancement. I will defend, following Christine Overall, the position that in order to properly discuss moral arguments about enhancement techniques we should avoid global generalizations about enhancement processes and we should evaluate each case and situation individually (Overall 2009, 328).

Generally speaking I agree with the idea that culturally we seek human enhancement. But I suggest that this idea is too value-laden and needs to be more detailed, clarified and criticized. Otherwise, as Allen Buchanan states, we might be addressing «enhancement techniques or projects» without considering and assessing these techniques or projects as a part of the improvement of human functioning, human society and humanity as a whole (Buchanan 2008, 14).

\section{THREE TYPES OF HUMAN ENHANCEMENT TECHNIQUES}

Schermer and Bolt distinguish between mundane improvements or «enhancements», on the one hand, and «Enhancements» on the other. Mundane improvements include techniques such as meditation, education and training as well as biomedical enhancement such as «breast implants, enhancing height by growth hormone, or improving one's personality or behavior with psychopharmacology» (Schermer and Bolt 2011, 179). These examples form part of the paradigmatic cases of «enhancement» and consist of an improvement of human functioning. The ethical debate about various kinds of techniques - pharmacological, biomedical or educational- is different, as I will seek to explain, from the debate about the «Enhancements» promoted by transhumanists.

One of the best-known defenders of transhumanism, Nick Bostrom, argues that «current human nature is improvable through the use of applied science and other rational methods, which may make it possible to increase 
human health-span, extend our intellectual and physical capacities, and give us increased control over our own mental states and moods» (Bostrom 2005a, 203-4).2 The new, upgraded and improved human -that genetic engineering, drugs, biomedicine or molecular nanotechnology could design and construct- is the topic of the ethics of human enhancement. «Enhancements» with a capital «e», as suggested by Schermer and Bolt, are sought by posthumanists. Better sight, cognition, mood, morality, feelings and physical functioning are part of the transhumanist dream. Transhumanists regard humans as being disabled, and look to pills, biomedical techniques and future developments in nanotechnology as ways to go beyond humanity (Bostrom 2005a; 2005b). The ethics of human enhancement is thus a new field of inquiry. In Bostrom and Savulescu's words, (bio)ethics nowadays deals with issues that have «moved from the realm of science fiction to that of ethics» (Bostrom and Savulescu 2009, 19).

Mundane improvements include, therefore, different kinds of practices that can be biomedical or not. For instance, the use of caffeine, education, training, meditation, breast implants or prenatal genetic diagnosis favor human enhancement, but these techniques do not constitute such a radical changing of «present humans as to no longer be unambiguously human by our current standards» (Wolfe 2009, xiii). Within this framework, only a certain number of the new biomedical enhancements, i.e. those which would serve to improve human functioning and capacities, would be on the way to realizing the transhumanist dream, even more so than the idea of improving human capacities would be. For instance, when scholars discuss the spread of those existing drugs used for therapy in order to improve human mood, they go beyond the mere idea of restoring and maintaining health, or improving human functioning. Instead, they open the door to questions such as those regarding a new sense and sensibility for posthumanity, a new type of feelings demanded by societal pressure and so on. For instance, pills could enable parents to feel love for adoptive children from the very first moment. Pills could also shape our emotions in accordance with social requirements (Kahane 2011, 174; Liao and Roache 2011, 245).

Schemer and Bolt's distinction is useful in order to frame the current ethical debate about human enhancement. However, their distinction could be improved, so that it would instead propose that the human enhancement debate

2 Transhumanity is conceived of as «the enhancement of human intellectual, physical, and emotional capabilities, the elimination of disease and unnecessary suffering, and the dramatic extension of life span» (Wolfe 2009, xiii). In sum, transhumans can be understood as «humans who have been so significantly modified and enhanced that there are significant non-human characteristics» (Savulescu 2009, 214). 
should be sensitive to three different types of enhancement techniques. The first type of technique is that of spreading practices from education, meditation or training that do not imply biomedical techniques; the second type relates to biomedical enhancements that do not, in principle, aim to transform humans into transhumans. Biomedical enhancements such as the use of vaccines or the use of assisted reproductive technologies fit within this second type of technique. The reason that I distinguish between the first and second types of techniques is the following. Firstly, the ethical debate on human enhancement, following Savulescu and Bostrom (2009, 3), should be considered to be a new kind of ethical enquiry, since the ethics of biomedical and pharmacological enhancement demand a more complex methodology than other ethical issues. In my view, this methodology must be a case-oriented one. Secondly, understanding and assessing human enhancement should be tackled within the frame of a new array of possibilities allowed by developments in biomedicine and the life sciences. Biomedical enhancements should thus be differentiated from other more mundane and less sophisticated techniques that are less risky or controversial, and that rely on other social and cultural values. For instance, on the one hand, educational techniques upgrade human memory and intellectual capabilities, which are desirable because literacy and knowledge are valued socially. Educational techniques can therefore help humans to improve their decision-making capacities. On the other hand, drugs such as modafinil (Provigil in the USA) are more effective for the task of improving human decision-making and intellectual capabilities in the short term. Based on the most current research, modafinil is a drug that improves decision-making processes in patients with schizophrenia or attention deficit hyperactivity disorder (ADHD) as well as in healthy people without any kind of neurological or psychological disorder (Sahakian and Labuzzeta 2013). Called «go pills» in the US, modafinil promotes alertness, concentration and more accurate responses in the decision-making process during military operations (Lin, Mehlman and Abney 2013, 23). Modafinil (Provigil) is thus a smart drug and it is considered to be part of the next generation of neurological drugs. From an ethical point of view, the use of modafinil has been seen as a moral good for healthy people who want to upgrade their intellectual capabilities (at university, for instance), or for those who wish to improve their alertness when they have to perform professional tasks in the context of sleep deprivations; users include soldiers, pilots and medical professionals (Lin, Mehlman and Abney 2013, 85; Enck 2013, 48-49). The use of modafinil in healthy people poses certain scientific, political, social and ethical problems, such as: Is the use of modafinil safe enough? Should children use modafinil in order to improve their performance at school? How 
should teachers and the educational system as a whole face a new generation of students that use modafinil to enhance their mental functioning enormously, carrying out their scholastic tasks with substantially less effort? Who would be left behind as a result of that enhancement? Without a doubt, the use of a smart drug is much more sophisticated than the use of other techniques that work as cognitive enhancers, such as caffeine or education. The use of a smart drug has more effect on society than the use of non-biomedical enhancers.

Going back to the three-way division among techniques I introduced above, the third type of technique focuses on radical future transformations of human capacities, and embraces the transhumanist dream. Such a position arises from the idea that science and technology can introduce improvements that no human being has yet evidenced (Bostrom 2005b, 6). More intelligent, physically upgraded and psychologically enhanced by the use of pharmaceutical neuroenhancements, transhumans or posthumans are what will come after the age of humans. These new «upgraded» humans could live much longer than mere humans, and could successfully take on very complex intellectual tasks and design technical solutions for present and future problems, all without effort. Bostrom, who embraces Drexler's vision of the future power of nanotechnology, explains his hopes for nanotech: «molecular nanotechnology would enable us to transform coal into diamonds, sand into supercomputers, and remove pollution from air and tumors from healthy tissues» (Bostrom 2005b, 9).

One important question that arises from the division of enhancement techniques into three types of techniques is that the acceptance of mundane enhancements -biomedical or not, such as meditation or the use of vaccines-is not a sufficient reason to unconditionally accept all biomedical, pharmaceutical or genetic enhancements. Agreement with certain kinds of enhancements is also not a valid reason for embracing a transhumanist position.

Enhancement techniques are controversial. We can be in favor of some vaccines and against the use of others; we can appreciate human life and can work for having an extension of lifespan without dreaming of immortality. Maybe we don't worry about bionic humans if this is the means to fighting against sickness. But these ideas are far from meeting the desires and goals of the transhumanist dream. Thus, the smartest thing to do, following Christine Overall (2009), would be to evaluate and assess each type of enhancement individually.

On balance, the simplistic view of enhancements as being unambiguously moral goods makes it difficult to think of different sorts of so-called «enhancements» and to assess them individually. It would be better, therefore, to analyze enhancements from the point of view of their scope, their cultural specificities, 
their entanglement with legislation and with social beliefs. A division among three types of enhancement techniques, like the division I have proposed above, would allow a better framing of the debate on human enhancement. From this point of view, the new ethical inquiry into human enhancement would deal with biomedical enhancements belonging to the second and third types of techniques, which are more sophisticated than the first type.

\section{THE EPISTEMOLOGICAL AND POLITICAL BACKGROUND OF THE ETHICAL DEBATE ON HUMAN ENHANCEMENT}

In Western thought, ${ }^{3}$ ethical reasoning about enhancement leads us, on the one hand, to bioconservative calls for respecting human nature and human autonomy and a concomitant refusal to permit the enhancing of human capacities. As Nick Bostrom states, the bioconservative camp includes religious believers, people who work from the deontological standpoint, anti-globalization activists and Asian perspectives (Bostrom 2005b, 3; Ida 2009; Shimazono 2009). Posthumanists, on the other hand, embrace consequentialism, and within consequentialism they follow the branch of utilitarianism that, in a broad sense, focuses on how normative properties depend respectively on consequences and on the maximization of utility. More particularly, as Julian Savulescu summarizes, bioconservative ethical reasoning can be characterized as humanistic and grounded in a «humanist prejudice», while posthumanist reasoning is grounded in personism: this is Peter Singer's original idea, the claim that what we value in humans does not depend on the species that human beings belong to (Savulescu 2009, 216-222). There is also a second group who uphold posthumanism within an ethical framework, i.e. the transhumanist movement (Bostrom 2005a). Posthumanism from the transhumanist perspective is partially grounded in secular humanist thinking, and aims to alter human nature by the responsible use of science and technology to overcome the limits of human functioning.

There are two main consequences that stem from the previous characterization of the ethical debate on human enhancement. The first is that both

3 I distinguish within the bioconservative branch a Western and an Asian point of view. Bioconservatives such as Sandel argue in terms that relate to a religious interpretation of nature and therefore also of human nature. Scholars working from an Asian perspective, such as Ida (2009) and Shimazono (2009), argue against enhancement techniques in the terms of reasons grounded in Asian cultural perspectives that fit well with the Asian concept of nature. In addition, they disagree with the Western stress on attaining mastery of nature through science and technology. 
bioconservatives and posthumanists are much too confident in the power of science and technology to change human nature. The second is that a positivist conception of technoscience prevails in the posthumanist framework, which emphasizes a view of science and technology that sees them as the best tools or means for reaching our political goals or ends. Transhumanists believe that the responsible use of the results of technoscientific advances should suffice to ensure the best consequences for the improvement of human functioning.

However, a better way of framing the human enhancement debate demands a critical review of scientific and technological practices qua value-laden enterprises. Along this line, great efforts have been applied in the philosophy of technoscience as well as in the interdisciplinary field called Science and Technology Studies (STS). From this point of view, science is not considered to be an exclusively cognitive activity that researches the true laws of nature, nor is technology considered to be an applied science that seeks to master nature. Technoscience is understood as both a cultural practice and as a subject susceptible of being democratized.

From the point of view of the democratization of technoscience, science and technology are cultural practices that aim to understand, create and transform reality. Scholars from a wide array of disciplines -sociology, anthropology, cultural studies, philosophy, political theory and history- investigate and analyze technoscientific practices, along with the socio-political elements that frame research and shape society and ontology. ${ }^{4}$ The critical review of the debate on human enhancement and the reflections that I will sketch are influenced by findings in STS concerning ways of conceiving scientific knowledge and technological practices, as well as ways of dealing with the politics of science and technology. In addition, the idea that the public plays no role in the governance of science and technology has been strongly contested (Brown 2009). Science and technology are held to be the best tools for forming public policies from a neutral, objective, non-subjective and non-political perspective. This claim was at the core of a rationalistic and instrumentalist tradition within political liberalism. But the idea that science should be considered a neutral means to

4 This last topic has been tackled through two main approaches. The first is associated with postmodernism, which focus on Foucauldian governmentality, poststructuralism and/or postfeminism. The second, which fits better with my interests, is centered on the promotion of democracy within the practice of science and technology, since it is not possible to consider science and technology to be value-free activities. Scholars such as Collins and Evans, Jasanoff, Latour and Wynne are representative of this second branch. See Jasanoff (2005); Collins and Evans (2007); Latour (1999); and Wynne (1992). 
reach political aims failed. Science and technology studies challenge this biased principle of instrumentalism (Ezrahi 1990; Brown 2009).

Therefore, reflections upon human enhancement from a moral point of view should certainly at least include some clues about the role of the public framing of so-called enhancements. The debate about improvements should include the public's desires, hopes and expectations, and should also recognize possible skeptical approaches to the promises of human enhancement that stem from science and technology. Furthermore, the new ethical inquiry that is undertaken should be sensible to political and cultural questions and current legislation. This is what I call the principle of non-isolationism, in virtue of which ethical reflection should take into account epistemological, social, cultural and political questions because they are intertwined and overlapped. For instance, modafinil (or Provigil) is considered to be a drug that works as a cognitive enhancer. Scholars in the academic debate see modafinil as a moral good (Lin, Mehlman and Abney 2003; Sahakian and Labuzzeta 2013). For students, modafinil is a «study drug», which they use in order to improve their results. ${ }^{5}$ The use of modafinil certainly improves concentration, alertness and mental task-orientation in healthy people in the short term. However, the use of modafinil entails certain scientific and political controversies that should be shaped not only by the academic discussion, but also by the political and public debate. Scientific evidence shows that modafinil is a cognitive enhancer in the short term, but there is a lack of evidence in the long term. Certain studies suggest that children should not use modafinil because their brain is still developing (Sahakian and Labuzzeta). In addition, modafinil could potentially be addictive. The ethical inquiry into human enhancement should thus pay attention to these controversial dimensions of smart drugs such as modafinil, as well as other dimensions related to «fair study» policies at college. In addition, there are repercussions for the educational system as a whole, e.g. the idea that various social problems, such as the low level of the population's literacy and knowledge, or their lack of concentration at work, could be solved by the use of pills. As Sahakian and Labuzzeta state: «it would be a true tragedy if these medications came to replace intellectual development through life-long learning, or resulted in an over-reliance on a pill to fix one's work-life balance» (Sahakian and Labuzzeta 2013, 130).

However, it seems that posthumanists such as Bostrom and Roache believe that the technoscientific and political realms must remain separated. Smart policies, in their assessment, should take into account the fact that enhancing the

5 See Cox (2013). 
human condition «delivers significant social, cultural, financial, and scientific benefits» (Bostrom and Roache 2011, 146). In addition, some posthumanists exhibit uneasy feelings regarding public policies because they are conservative in regards to cognitive enhancement (Sandberg and Savulescu 2011, 93), mood enhancement (Bostrom and Roache 2011, 143-146) or physical enhancement (Savulescu and Foddy 2011, 310). Provided that science offers the means to master human nature in a given case, posthumanists think, government policies should allow putting those enhancements that would be feasible into practice. As a consequence, we see that (i) both positions are too confident about science and technology as a tool for implementing public policies; (ii) posthumanists and bioconservatives think of science and technology in terms of mastery and control of nature; however, what is required, from the point of view of supporters of the creative framework, is a responsible use of technoscience; (iii) it appears that posthumanists do take stances about what should be desirable from an ethical point of view, and that the task of politics should consist of developing health policies according to developments in human enhancements.

\section{BEYOND OPTIMISM AND PESSIMISM: VIEWS ON HUMAN ENHANCEMENT}

The ethical debate concerning human enhancement -in the terms established in the debate between bioconservatives and posthumanists- is not interwoven with social and political issues. Bioconservatives assess the power of enhancement techniques negatively because they believe that through those techniques human nature would be changed, a change that deserves to be rejected from a moral point of view. Posthumanists, on the other hand, hold that science and technology make human enhancements possible, and that these improvements are objectively moral goods. No matter how a society is structured, technoscientific advances in human enhancement should always be welcome (Savulescu, Sandberg and Kahane 2011, 6). In their view, humans will have strong moral reasons to care about transhumans because they will embody what these thinkers consider to be the most valuable goods in persons: reason and self-consciousness (Savulescu 2009, 217- 220). In spite of this, «enhancements $[\ldots]$ currently face specific regulatory problems, which may impede advances» (Sandberg 2009, 72).

Both ethical frameworks exhibit a lack of reflection on the new realities resulting from such technoscientific practices as enhancement, bionics and hyper-smart humans, and on whether the society will accept or reject specific modifications. On the one hand, bioconservatives and posthumanists do not 
deal with the transformation of societies as they adapt to these new realities. They do not inquire into how theories of justice should evolve in order to tackle new problems emerging from the new restructuring of society. ${ }^{6}$ On the other hand, posthumanists are optimistic about new realities made possible by science and technology. They consider that enhancement techniques will contribute to creating an objectively better world.

As a consequence, I argue that positivism within the creative or posthumanist framework concerning human enhancement is accompanied by an optimism grounded in the imperfection and disability of human nature, which leads to a disenchantment concerning what is considered human, and in turn leads to efforts to promote transhumanity (Savulescu, Sandberg and Kahane 2011, 14). In spite of this, I consider this to be an issue that deserves attention, taking into account the social and cultural framework that will be affected by enhancement, as well as attention from a philosophical, moral and legal perspective. This point of view is in accordance with Roberto Mordacci's ideas, which argue against the positivism and optimism of posthumanists and challenge their aims of promoting a better humanity: «it seems that at present we do not possess the cultural, theoretical, and political tools to face these changes» (Mordacci 2011, 418).

Furthermore, there is also a lack of reflection on the re-definition of the relationships between humans and enhanced humans that might result from those so-called improvements. For bioconservatives, the issue does not deserve any attention, since their ethical arguments center on how to preserve human dignity and how to appreciate human life and fulfill the promise inherent in «human nature». Posthumanists rely too much on transhumans as beings that embody and perfect valuable features of humans. In so doing, scholars within the transhumanist camp argue in favor of enhancement of human capacities and «Enhancements», but their arguments suffer from ambiguity in at least two senses. First, they discredit, on the one hand, the idea that ethical reflection on human enhancement should be linked to a theory of justice embedded within social, economic and political contexts. And, on the other hand, as we have seen, they argue that the ethical implications of human enhancements should suffice to justify public policies that support enhancements and Enhancements. Secondly, transhumanists are also ambiguous when they argue for a new type of ethical approach to enhancement issues, since the long-standing methods currently employed in ethics are ill-equipped to tackle the problems and pos-

6 See Mordacci (2011) for a reflection on the theory of justice in the era of lifespan extension. 
sibilities for humanity that are posed by progress in science and technology. But at the same time, most of the arguments in favor of enhancement -apart from the naïve idea sketched before that human enhancement is a clear path to a better world- are based on the idea that enhancement techniques have always been used by humans. Posthumanists thus do not see any reasons for not developing new genetic, biomedical or robotic techniques in order to improve humans. As a result, these scholars do not pay attention to the fact that they are reproducing a moral justification for enhancement that is based on the fact that enhancement is already a current practice; it thus reproduces, in my view, the naturalistic fallacy.

\section{Vi. CONCLUSIONS}

I would like to highlight two main conclusions deriving from my argument above. The first is that certain findings within STS, such as the conception of scientific knowledge, the social and political appraisal of technoscientific practices and the entanglement of science and technology with legislation and cultural practices, are valuable in order to think through the moral implications of human enhancement. All these issues help us to think in depth about certain missing aspects of ethical reflection on human enhancement that relate precisely to the non-isolationism principle.

The second consequence concerns the necessity of framing anew the ethical debate on human enhancement in order to supersede the bioconservative and pro-enhancement positions in ethics: first of all, this dualistic way of framing the debate does not fit well with all the great variety of ways of improving human capacities, and makes it difficult to differentiate mundane enhancements from «Enhancements» that lead to transhumanism. The distinction between three types of enhancement techniques that I have sketched would be useful for investigating and discussing the individual improvements at stake.

\section{REFERENCES}

BOSTROM, NICK. 2005a: «In Defense of Posthuman Dignity». Bioethics 19, 3: 202-214.

BOSTROM, Nick. 2005b: «A History of Transhumanist Thought». Journal of Evolution and Technology 14: 1-25. 
BOSTROM, NICK and SAVULESCU, JULIAN. 2009: «Human Enhancement Ethics: The State of the Debate». In Human Enhancement, Julian Savulescu and Nick Bostrom, eds., Oxford: Oxford University Press, 1-22.

BOSTROM, NICK and ROACHE, REBECCA. 2011: «Smart Policy: Cognitive Enhancement and the Public Interest». In Enhancing Human Capacities, Savulescu, Ruud Meulen and Guy Kahane, eds., Oxford: Wiley-Blackwell, 138-149.

BROCK, DAN W. 2009: «Is Selection of Children Wrong?». In Human Enhancement, Julian Savulescu and Nick Bostrom, eds., Oxford: Oxford University Press, 251-276.

BROWN, MARK B. 2009: Science in Democracy: Expertise, Institutions, and Representation. Cambridge, MA: MIT Press.

BUCHANAN, ALLEN. 2008: «Enhancement and the Ethics of Development». Kennedy Institute of Ethics Journal, 18-1: 1-34.

COLLINS, HARRY and EVANS, ROBERT. 2007: Rethinking Expertise. London and Chicago: The University of Chicago Press.

COX, DAVID. 2013: «Is Modafinil Safe in the Long Term?». The Guardian, May 31. Section "Blogging Students."

ENCK, GAVIN G. 2013: «Pharmaceutically Enhancing Medical Professionals for Difficult Conversations». Journal of Evolution and Technology 23, 1: 45-55.

EZRAHI, YARON. 1990: The Descendent of Icarius. Cambridge, MA and London: Harvard University Press.

HARRIS, JOHN. 2009: «Enhancements Are a Moral Obligation?». In Human Enhancement, Julian Savulescu and Nick Bostrom, eds., Oxford: Oxford University Press, 131-154.

IDA, RYUICHI. 2009: «Should we Improve Human Nature? An Interrogation from Asian Perspective». In Human Enhancement, Julian Savulescu and Nick Bostrom, eds., Oxford: Oxford University Press, 59-70.

JASANOFF, SHEILA. 2005:. Designs on Nature. Science and Democracy in Europe and the United States. Princeton: Princeton University Press.

JUTH, NIKLAS. 2011: «Enhancement, Autonomy and Authenticity». In Enhancing Human Capacities, Julian Savulescu, Ruud Meulen and Guy Kahane, eds., Oxford: Wiley-Blackwell, 34-48.

KAHANE, GUY. 2011: «Reasons to Feel, Reasons to Take Pills». In Enhancing Human Capacities, Julian Savulescu, Ruud Meulen and Guy Kahane, eds., Oxford: Wiley-Blackwell, 166-178.

LATOUR, BRUNO. 1999: Politiques de la nature. Comment faire rentrer les sciences en démocratie. Paris: La Découverte. 
LIAO MATTHEW, S. and ROACHE, REBECCA. 2011: «After Prozac». In Enhancing Human Capacities, Julian Savulescu, Ruud Meulen and Guy Kahane, eds., Oxford: Wiley-Blackwell, 245-256.

LILLEY, STEPHEN, 2013: Transhumanism and Society. The Social Debate over Human Enhancement. Dordrecht, Heidelberg, New York, and London: Springer.

LIN, PATRICK, MEHLMAN, MAXWELL J. and ABNEY, KEITH. 2013: Enhanced Warfighters: Risks, Ethics and Policy. (January 18, 2013). Case Legal Studies Research Paper No. 2013-2. Available at SSRN: http://ssrn. com/abstract $=2202982$

MORDACCI, ROBERTO. 2011: «Intergenerational Justice and Lifespan Extension». In Enhancing Human Capacities, Julian Savulescu, Ruud Meulen and Guy Kahane, eds., Oxford: Wiley-Blackwell, 410-420.

NIELSEN, LISBETH WITTH $\square$ FFT. 2011: «The Concept of Nature». In Enhancing Human Capacities, Julian Savulescu, Ruud Meulen and Guy Kahane, eds., Oxford: Wiley-Blackwell, 19-33.

OVERALL, CHRISTINE. 2009: «Life Enhancement Technologies: Significance of Social Category Membership». In Human Enhancement, Julian Savulescu and Nick Bostrom, eds., Oxford: Oxford University Press, 327-240.

PARENS, ERIK. 2005: «Authenticity and Ambivalence. Toward a More Fruitful Debate About Human Enhancement». The Hastings Center Report 35, 3: $34-41$.

PARENS, ERIK. 2009: «Toward a More Fruitful Debate About Human Enhancement». In Human Enhancement, Julian Savulescu and Nick Bostrom, eds., Oxford: Oxford University Press, 181-198.

SAHAKIAN, BARBARA and LABUZZETA JAMIE, NICHOLE. 2013: Bad Moves. How Decision-making Goes Wrong and the Ethics of Smart Drugs. Oxford: Oxford University Press.

SANDBERG, ANDERS. 2009: «Cognition Enhancement: Upgrading the Brain». In Savulescu, Julian; Meulen, Ruud; Kahane, Guy, eds., Enhancing Human Capacities. Oxford: Wiley-Blackwell, 71-91.

SANDEL, MICHAEL J. 2009: «The Case Against Perfection: What's Wrong with Designer Children, Bionic Athletes, and Genetic Engineering». In Human Enhancement, Julian Savulescu and Nick Bostrom, eds., Oxford: Oxford University Press, 71-89.

SAVULESCU, JULIAN. 2009: «The Human Prejudice and the Moral Status of Enhanced Beings: What Do We Owe the Gods». In Human Enhancement, Julian Savulescu and Nick Bostrom, eds., Oxford: Oxford University Press, 211-247. 
SAVULESCU, JULIAN; SANDBERG, ANDERS and KAHANE, GUY. 2011: «Well Being and Enhancement». In Enhancing Human Capacities, Julian Savulescu, Ruud Meulen and Guy Kahane, eds., Oxford: Wiley-Blackwell, 3-18.

SAVULESCU, JULIAN and FODDY, BENNETT. 2011: «Le Tour and Failure of Zero Tolerance: Time to Relax Doping Controls». In Enhancing Human Capacities, Julian Savulescu, Ruud Meulen and Guy Kahane, eds., Oxford: Wiley-Blackwell, 304-312.

SCHERMER, MAARTJE and BOLT, INELKE. 2011: «What's in a Name? ADHD and the Gray Arena between Treatment and Enhancement». In Enhancing Human Capacities, Julian Savulescu, Ruud Meulen and Guy Kahane eds., Oxford: Wiley-Blackwell, 179-193.

SHIMAZONO, SUSUMU. 2009: «Reasons Against the Selection of Life: From Japan's Experience of Prenatal Genetic Diagnosis». In Human Enhancement, Julian Savulescu and Nick Bostrom eds., Oxford: Oxford University Press, 291-314.

SINGER, PETER. 2009: «Parental Choice and Human Improvement». In Human Enhancement, Julian Savulescu and Nick Bostrom eds., Oxford: Oxford University Press, 277-290.

TEMKIN, LARRY. 2011: «Is Living Longer Living Better». In Enhancing Human Capacities, Julian Savulescu, Ruud Meulen and Guy Kahane ed., Oxford: Wiley-Blackwell, 350-367.

WOLFE, CARY. 2009: What Is Posthumanism? Minneapolis: University of Minnesota Press.

WYNNE, BRIAN. 1992: «Misunderstood Misunderstanding: Social Identities and Public Uptake of Science». Public Understanding of Science 1: 281-304. 
